\title{
Abundance and Structure of African Baobab (Adansonia digitata) across Different Soil Types in Gonarezhou National Park, Zimbabwe
}

\author{
Clayton Mashapa, ${ }^{1}$ Patience Zisadza-Gandiwa, ${ }^{2,3}$ Edson Gandiwa, ${ }^{4}$ and Shakkie Kativu ${ }^{1}$ \\ ${ }^{1}$ Tropical Resource Ecology Programme, Department of Biological Sciences, University of Zimbabwe, P.O. Box MP 167, \\ Mount Pleasant, Harare, Zimbabwe \\ ${ }^{2}$ Scientific Services, Gonarezhou National Park, Parks and Wildlife Management Authority, Private Bag Box 7003, Chiredzi, Zimbabwe \\ ${ }^{3}$ Transfrontier Conservation Areas Office, Parks and Wildlife Management Authority, P.O. Box CY 140, Causeway, Harare, Zimbabwe \\ ${ }^{4}$ Department of Wildife and Safari Management, Chinhoyi University of Technology, Private Bag Box 7724, Chinhoyi, Zimbabwe
}

Correspondence should be addressed to Clayton Mashapa; clayiemashapa@yahoo.co.uk

Received 7 May 2013; Revised 13 August 2013; Accepted 26 August 2013

Academic Editor: Arianna Azzellino

Copyright (c) 2013 Clayton Mashapa et al. This is an open access article distributed under the Creative Commons Attribution License, which permits unrestricted use, distribution, and reproduction in any medium, provided the original work is properly cited.

\begin{abstract}
This study investigated the abundance and structure of African baobab (Adansonia digitata) across soil group strata in Gonarezhou National Park, Zimbabwe. The study was based on a stratified random sampling design composed of the following soil group substrates: (i) granophyres, (ii) malvernia, and (iii) rhyolite. Belt transects of $0.3 \times 0.1 \mathrm{~km}$ were randomly laid across soil group. Baobab abundance and population structure were determined from the density and size class distribution, respectively. There were significant differences in plant height and plant density across Gonarezhou soil groups. Study sites on granophyres derived soil group indicated viable abundance and recruitment of baobab population. Whereas the study highlighted a concern over the unbalanced size structure distribution of baobab population on malvernia derived soil group, our results indicated that baobabs are in danger of extirpation on malvernia derived soil group. Baobab community in Gonarezhou tends to occur more densely along environmental gradient of soil group type as influenced by the underlying geological soil substrate of granophyres. Malvernia derived soil group is likely less ideal for baobab recruitment.
\end{abstract}

\section{Introduction}

Plant species distribution is usually modeled as a function of climatic, geologic, or edaphic variables, which are postulated to exert a prominent effect on species' natural distribution $[1,2]$. The stability and complexity of large expanses of woodlands in semiarid savanna in face of soil resource gradient continue to stimulate debate on plant species regeneration concept [3]. In Gonarezhou National Park (hereafter, Gonarezhou), Zimbabwe, soil group variation is perceived as a determinant for African baobab (Adansonia digitata) abundance and spatial population structure distribution, as soil group resource type may compensate or aggravate climatic aridity as well as soil nutrient availability. Landscape-scale variation in woody vegetation may primarily relate to soil group nutrient resources [4]. In recent years, baobab population seems to show unusually low recruitment in central parts of Gonarezhou, despite low elephant (Loxodonta africana) density [5] and low fire frequency [6] within the central Gonarezhou. This phenomenon is associated with likely future local extirpation of a species. Such a trend deserves investigation and monitoring.

Baobab is a key note species of ecological significance in the savanna ecosystem, and thus it is a protected species in South Africa [7]. In Zimbabwe, baobab is confined to semiarid low altitude areas [8]. It provides forage opportunities and refuges for a myriad of species and also plays a key role in nutrients cycling and soil conservation $[9,10]$. Studies of plant species regeneration response to soil resource gradient in various parts of the world continue to provide more 
information [4]. Gonarezhou presents an excellent opportunity for such a study. If stable baobab populations were perceived to follow one region and one climax hypothesis, then perceived progressions or retrogressions could also be explained in support of conventional Clementsian monoclimax theory, thus expecting Gonarezhou baobab community in different soil group substrate strata to be at the same state and transition towards its climax state [11]. The present study aimed at providing information on status of baobab abundance, structure, and recruitment at landscape-level dynamics in Gonarezhou, subject to soil variation based on soil group types derived from three geological substrates strata, namely, granophyres, rhyolite, and malvernia.

\section{Materials and Methods}

2.1. Study Area. Gonarezhou has been part of Great Limpopo Transfrontier Park comprising parts of Mozambique, South Africa, and Zimbabwe since 2000. It is located in southeast lowveld of Zimbabwe, between latitudes $21^{\circ} 00^{\prime} \mathrm{S}$ to $22^{\circ} 15^{\prime} \mathrm{S}$ and longitudes $30^{\circ} 15^{\prime} \mathrm{E}$ to $32^{\circ} 30^{\prime} \mathrm{E}$. It covers an area of $5,053 \mathrm{~km}^{2}$ [13]. Mean annual precipitation for Gonarezhou (1972-2012) is $447 \mathrm{~mm}$ and has varied between $92 \mathrm{~mm}$ in 1992 and $1115 \mathrm{~mm}$ in 2000 [13]. Droughts (annual rainfall less than $200 \mathrm{~mm}$ ) are a characteristic of Gonarezhou [12]. The climate of Gonarezhou, therefore, may be regarded as semiarid [14].

Soil group substrate strata were delineated according to Gonarezhou geological map [12, 15]. Geological soil formations of granophyres and malvernia substrates in Gonarezhou (Figure 1) cover nearly $95 \%$ of the park, and areas of alluvial and rhyolite substrates constitute the remaining area $[16,17]$. About five categories of soil type based mainly on colour, depth, and amount of calcareous material incorporated in soil can be recognized, namely, lithosol, regosol, vertisol, siallitic, and sodic groups [17]. Granophyres geological types give rise to shallow soils particularly on upland terrain [15]. Malvernia derived soil group gives rise to undulating plains of poorly drained deep clay loams; in depressions, the soils tend to be sodic because of the relatively high amounts of exchangeable sodium [17].

Broadly, the two main vegetation types in Gonarezhou are mopane (Colophospermum mopane) and sandveld woodlands/thickets which cover about $80 \%$ of the park $[12,18]$. Mopane is mostly distributed along the larger river valleys on alluvial soil group and is found in low altitude, low rainfall areas that coincide with high temperature [19]. Dry deciduous sandveld woodland and scrub vegetation community occurs predominantly on sandstone uplands with deep sandy loamy soils [12].

2.2. Study Design and Sampling Procedure. Our study was based on a stratified random sampling design on the basis of soil group substrate gradient $[6,20]$. Soil group substrate delimitation was based on geological soil map as shown in Figure $1[12,15]$. Belt transects were randomly placed using random number tables based on Gonarezhou topographical map grid square intercept system. Belt transects of size $0.3 \times$ $1.0 \mathrm{~km}$ were randomly laid in the defined soil group substrates strata [21]. For the purpose of this study, belt transects of $1 \mathrm{~km}$ length were used because baobabs were sparsely distributed and the species is not dominant in Gonarezhou.

Baobabs within a defined belt transect were all sampled and those occurring along belt transect margins were sampled if at least half the canopy was inside the belt transect [19]. Some trees still had leaves and fruits during the study period of May 2012, and this made species identification easier. Baobabs were identified at sapling or seedling stage from field guide [8]. To investigate cumulative and interactive determinants of soil group substrate on baobab population structure and abundance, baobab plant height and basal stem circumference were measured [22]. Plant height was measured to the nearest metre by placing a calibrated $12 \mathrm{~m}$ pole against the plant. For trees $>12 \mathrm{~m}$, the pole was manually uplifted or height visually estimated by observing it at a distance away from the tree. Basal circumference of each stem was measured at breast height $(1.3 \mathrm{~m})$ to the nearest centimetre, using a flexible $50 \mathrm{~m}$ tape measure. Where plant height was less than $1.3 \mathrm{~m}$, basal stem circumference was measured just above buttress swelling. For multistemmed plants, only the height and the basal circumference of the tallest stem were considered.

\section{Data Analysis}

Variables in analyses were baobab height, basal area, density, and grass height. Data were tested for normality using the Kolmogorov-Smirnov test in STATISTICA version 6 for Windows [23]. Data on baobab height, density, and grass height were normal. Data on basal area were $\log _{10}(y+1)$ transformed, where $y$ is the measured variable quantity, in order to satisfy the assumptions of normality and equality of variance. Data were summarized by descriptive statistics (means and standard errors) per each belt transect before further analyses. Baobab density was calculated from the following formula: density = numbers of baobab in a study site and then converted to ha ${ }^{-1}$. From basal stem circumference, basal area was calculated using the following formula: basal area $=$ $\left(C^{2} / 4 \pi\right)$, where $C$ is basal stem circumference. From basal stem circumference, diameter at breast height $(\mathrm{DBH})$ was calculated using the formula $\mathrm{DBH}=C / \pi$. A one-way analysis of variance (ANOVA) with Gonarezhou soil group substrates as grouping variables and measured variables as dependent variables was used to find if there were significant differences in baobab population structure and abundance across Gonarezhou soil group strata. Statistical significance was considered at $P \leq 0.05$.

Data were further analyzed through a combination of classification and ordination techniques to explore associations, patterns, and structure of baobab structure and abundance across three soil group substrate strata. This further analysis was done in order to determine whether different baobab stands, belt transects, could be distinguished from each other based on defined soil group substrate variation. We performed two different analyses, namely, principal component analysis (PCA) and hierarchical cluster analysis (HCA). We used PCA to define both pattern and structure of variables [24] in different soil group strata using the measured baobab variables. HCA using weighted pair group average linkage method was performed using a matrix of 14 


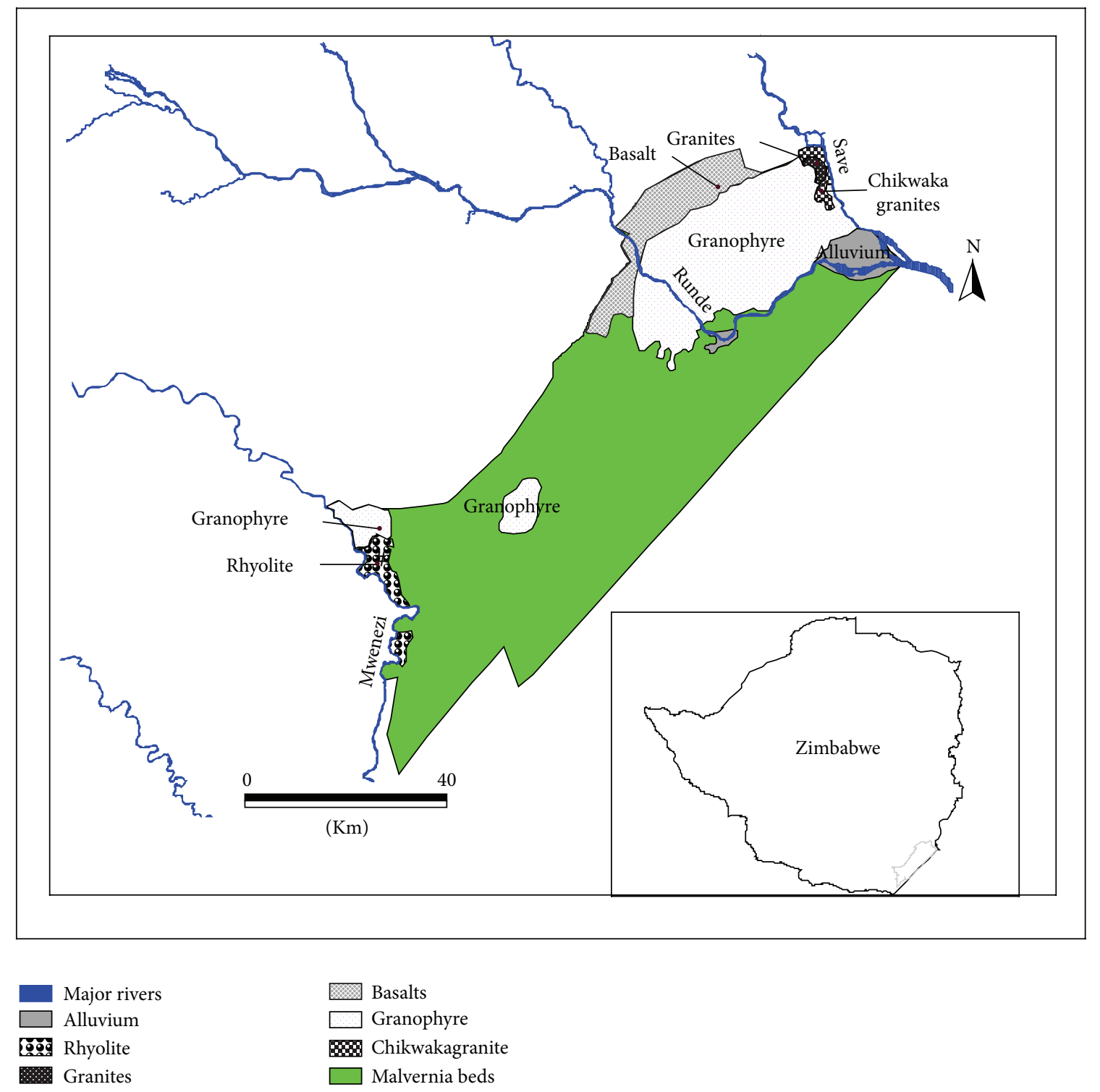

FIGURE 1: Geological map of Gonarezhou National Park showing various soil group substrates. Source: [12].

belt transects and baobab abundance and structure data, to classify sampling belt transects on the basis of their baobab demographic similarity across soil group substrates strata.

Baobab size class categorization was based on $2.5 \mathrm{~m}$ intervals of DBH [22]; that is, sampled baobabs were represented as number of individuals per size class based on the following: baobab saplings were of DBH size class $\leq 2.5 \mathrm{~m}$, juvenile baobabs were of DBH size class $2.5 \mathrm{~m}<\mathrm{DBH} \leq 5 \mathrm{~m}$, subadult baobabs were of DBH size class $5 \mathrm{~m}<\mathrm{DBH} \leq 7.5 \mathrm{~m}$, and adult baobabs were of DBH size class $>7.5 \mathrm{~m}$. Demographics of baobab sampled within a particular soil group substrate stratum were represented as percentage frequency size class distributions representing baobab populations in different soil group substrates strata. These distributions were derived from sampled baobab of uniform size class (DBH) interval categories, which were used to trace growth patterns of equal individual's numbers of baobab across soil group type, as it gives an indication of recruitment at any particular stage in population history [7]. A Chi-square independence test to compare baobab size (DBH and height) across soil type was done, using equal number of baobabs sampled on each soil substrate study stratum.

\section{Results}

4.1. Baobab Abundance and Population Structure. We surveyed 14 belt transects and a total of 283 baobabs were sampled. The highest number of 189 baobabs was observed on granophyres derived soil group, followed by 66 observed on rhyolite soil type, whereas the least number of 28 baobabs was observed on malvernia derived soil group type. The smallest baobab sampled had a plant height of $1 \mathrm{~m}$ with a DBH of $0.03 \mathrm{~m}$, whereas the largest had a plant height of $22 \mathrm{~m}$ with a DBH of $5.6 \mathrm{~m}$. The abundance of baobabs was relatively 
TABLE 1: Summary of statistical analysis (one-way ANOVA) of the measured variables.

\begin{tabular}{|c|c|c|c|c|c|}
\hline \multirow{2}{*}{ Variables } & \multicolumn{5}{|c|}{ Soil group substrate } \\
\hline & Granophyres & Rhyolite & Malvernia & $F_{2.22}$ & $P$ value \\
\hline Baobab height $(\mathrm{m})$ & $12.74 \pm 0.36$ & $9.23 \pm 1.75$ & $4.19 \pm 3.23$ & 4.08 & 0.047 \\
\hline Baobab density $\left(\mathrm{ha}^{-1}\right)$ & $1.16 \pm 0.23$ & $0.55 \pm 0.07$ & $0.19 \pm 0.16$ & 7.92 & 0.007 \\
\hline Baobab basal area $\left(\mathrm{m}^{2} / \mathrm{ha}\right)$ & $7.94 \pm 0.23$ & $4.97 \pm 1.41$ & $6.98 \pm 6.34$ & 0.13 & 0.877 \\
\hline Grass height $(\mathrm{m})$ & $0.62 \pm 0.14$ & $0.37 \pm 0.10$ & $0.24 \pm 0.04$ & 3.59 & 0.063 \\
\hline
\end{tabular}

clustered on granophyres and rhyolite substrates derived soil groups, while scarce and dispersed on malvernia substrate derived soil group. There was rare evidence of baobab on malvernia substrate derived soil group, where three of the surveyed belt transects had no record of baobab presence. There were significant differences in both baobab height and density across three soil group substrates strata. Belt transects on malvernia substrate derived soil group had both lowest baobab density and heights as compared to the other two strata (Table 1). In contrast, there were no significant differences in both basal areas of baobabs and grass height across three strata in Gonarezhou. Two percent of total sampled baobabs were dead, of which four were recorded on granophyres stratum and two on rhyolite stratum, and no dead baobab was observed on malvernia study stratum. Grass height across the study area showed no significant difference. Grass height could have affected visibility of baobab saplings during sampling.

PCA output of measured variables shows Factor 1 accounting for about $61.4 \%$ (eigenvalue $=0.65$ ) and Factor 2 accounting for about $27 \%$ (eigenvalue $=0.30$ ) of the variance (Figure 2) in baobab abundance and structure in the sample belt transects across the three strata in Gonarezhou. All measured variables were positively correlated with Factor 1 . Factor 1 therefore defines an increasing gradient from areas with short baobabs characterized with small basal areas to areas with taller baobabs with big basal areas. Basal area and height were negatively correlated with Factor 2, while baobab density was positively correlated with Factor 2. Factor 2 defines a gradient from areas with taller baobabs with bigger basal area to areas with higher baobab density. Consequently, belt transects with taller baobab and larger basal areas with higher baobab density scored high on Factor 1, mostly being sample belt transects falling in the granophyres and rhyolite derived soils, whereas those of shorter baobab and smaller basal area with a low baobab density scored low on Factor 1, mostly being sample belt transects from the malvernia derived soils. There was one outlier sample belt transect from the malvernia soil group stratum which scored high on Factor 1.

HCA dendrogram showed three broad subclusters from the 14 sampled belt transects in Gonarezhou (Figure 3). Subcluster A had an outlier sample belt transect from malvernia soil group stratum, which was characterized by the tallest baobab tree which had the largest basal area; however, the belt transect had low baobab density. Subcluster B had sample belt transects mainly drawn from malvernia derived soil group stratum. Belt transects in subcluster B were characterized by an association of the following factors: low baobab density

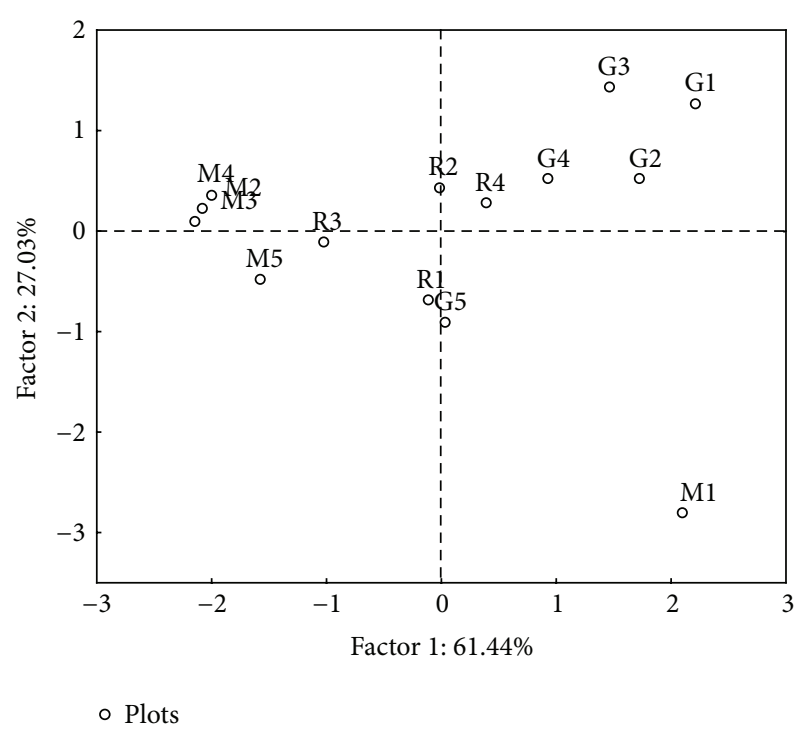

Figure 2: Principal component analysis scatter plot of 14 sample belt transects in Gonarezhou National Park, Zimbabwe. R denotes sample belt transects from the rhyolite derived soil group; $M$ denotes sample belt transects from malvernia derived soil group, and G denotes sample belt transect from granophyres derived soil group.

and smaller basal areas with shorter baobabs. Subcluster C comprised sample belt transects from both rhyolite and granophyres substrate derived soil groups and included the following common factor of association: taller baobabs and larger basal areas of higher baobab density.

\subsection{Baobab Recruitment and Regeneration across the Three} Soil Group Substrates. Figure 4 presents a summary of frequency distribution of baobab size class intervals of the first twenty-eight sampled individuals on each particular soil group substrate study stratum across Gonarezhou. Twentyeight was the common highest number of baobab individuals we observed on each of the three study strata, and a Chisquare independence test for comparing baobab height of uniform DBH size class interval showed significant difference across soil group substrate strata $\left(\chi^{2}=21.53, P<0.0001\right)$. The highest frequency of juvenile baobab size class, $\mathrm{DBH}$ of $\leq 5 \mathrm{~m}$, was found on granophyres soil group stratum. Baobab size class distribution on granophyres soil group stratum showed an inverse $J$-shaped size class distribution, with a smooth decline (monomodal distribution) in baobab numbers from a maximum in juvenile size class. Baobab 


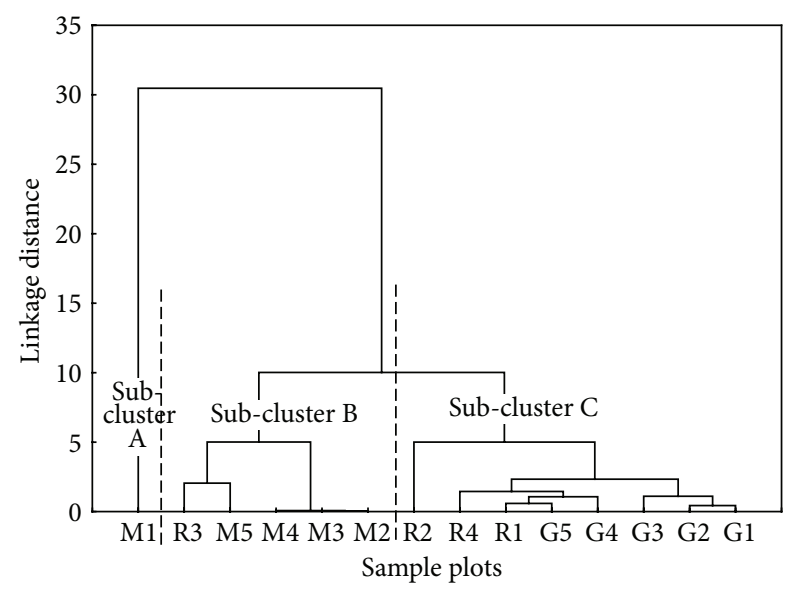

FIGURE 3: Hierarchical cluster analysis dendrogram showing classification of sample belt transects into three clusters based on species abundance data from the 14 sample belt transects in Gonarezhou National Park, Zimbabwe. R denotes sample plots from the rhyolite derived soils, $\mathrm{M}$ denotes sample plots from malvernia bed derived soils, and G denotes sample plots from granophyre derived soils.

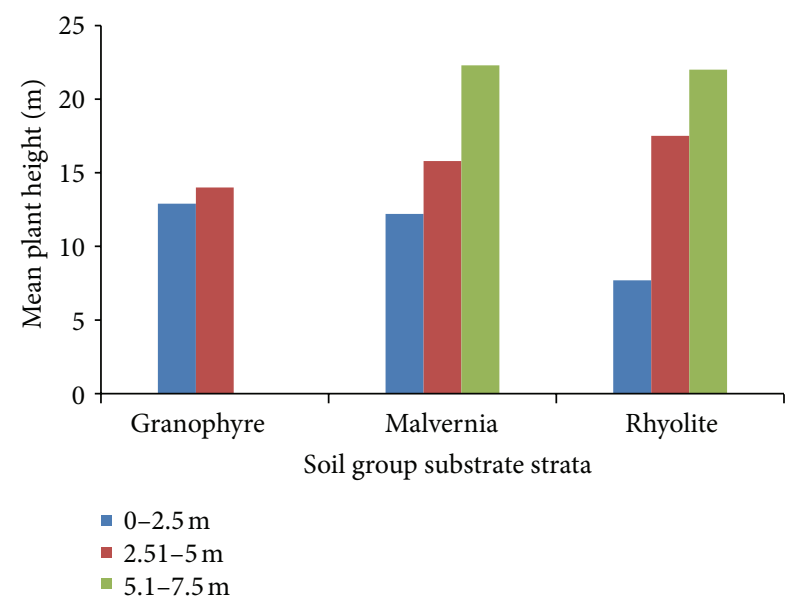

FIgURE 4: Size class distribution (DBH) of baobab across soil group substrate strata.

size class distribution on malvernia and rhyolite soil group stratum formed a bell-shaped or positively skewed size class distribution curve with a peak on adult size class (Figure 4).

\section{Discussion}

Our study recorded significant differences in baobab height and density across soil group substrate strata in Gonarezhou. The demographic and abundance differences in baobab population in Gonarezhou probably resulted from edaphic factors such as differences in soil nutrients, soil depth, soil drainage, soil moisture, and climatic induced aridity droughts. Taller heights of baobabs sampled in this study were clustered on the granophyres derived soil group which all give rise to moderate deep to shallow and highly permeable soils [15] of finely textured sandy loams that are highly calcareous
[17]. There were relatively shorter baobabs of low density on malvernia and rhyolite stratum. There was noticeable rare evidence of baobabs on malvernia derived soil group stratum, where we recorded no baobabs on three belt transects, despite low elephant density [5] and low fire frequency [6] recorded in this particular study stratum. Thus, this could be attributed to the fact that baobabs are known to grow on a wide range of well-drained soils, from clays to sands, but not on deep unconsolidated soils, where the species is unable to obtain sufficient moisture or anchorage [9]. In general, granophyres derived soils are relatively well drained as compared to the malvernia derived soil groups $[15,16]$, and this could be attributed to high abundance of baobab on granophyres derived soil group type, noting that [25] observed no significant difference in elephant impact on baobabs across Gonarezhou.

Baobab size (i.e., DBH and plant height), a good indicator of photosynthetic growth, significantly differed across soil group substrates; baobabs on granophyres substrate were relatively larger and taller, probably due to habitat soil texture, soil depth, soil drainage, or other edaphic factors like soil nutrients, soil structure, and soil water balance not measured in this present study which can affect plant growth. Soil texture and structure strongly influence soil water balance and therefore plant species community development [2]. The nonsignificant difference in basal areas of the total sample coupled with significant difference in baobab heights across Gonarezhou soil strata implies stunted growth of baobabs on malvernia derived soil group, which recorded the shortest mean baobab height.

Size class distribution of baobabs in Gonarezhou strata showed an inverse $J$-shaped size class distribution on the soil group substrates strata of granophyres. Such a pattern indicates a balance between recruitment and mortality of baobabs [26]. This suggested that baobab recruitment on granophyres derived soil group was relatively high and represents a steady state and transitional increasingly viable baobab population [27], despite high elephant density [5] and high fire frequency [13] within this particular study stratum. The classic inverse $J$-shaped size class distribution is generally used by biologists as an indication of a healthy, recruiting population, and deviation from this would normally be a cause for concern [26]. The argument is that a healthy viable and potentially growing population would have a reverse $J$ size-class distribution, with a smooth decline (monomodal distribution) in numbers from a maximum in the juvenile size class $[7,28]$. Baobab size class distribution on malvernia and rhyolite substrates strata had a positively skewed $J$-sized class distribution which indicated the existence of irregular growth patterns [9]. Thus, the present study highlighted and indicated a concern over the unbalanced size class structure distribution of baobabs on malvernia and rhyolite strata in Gonarezhou, which suggested a baobab recruitment bottleneck on malvernia and rhyolite derived soil group types. The present study confirmed the concept of regeneration niche [29] that speciesenvironment relationships may vary with plant life stage (size class); consequently, juvenile baobabs could have different requirements from adults and may therefore have different distribution patterns from adults. 


\section{Conclusion}

A central goal of plant ecology is to understand which factors influence local distribution and patterns of plant species [30]. A key to this focus was our observation that baobab community in Gonarezhou tends to occur more densely along environmental gradient of soil group as influenced by the underlying geological soil substrates of granophyres. Malvernia derived soil group type is likely less ideal for baobab abundance and recruitment. Our study results suggested that underlying geology which dictates soil group type is a key determinant for the pattern of baobab abundance, structure, and recruitment. This confirmed as was noted that, within southeastern Zimbabwe low altitude plains, variations in rainfall, altitude, and temperature are negligible, and consequently vegetation communities can be considered according to soil group types which generally change with variations in geological types [31].

We noted that the most important explanatory variables for baobab abundance, spatial structural distribution, and recruitment in Gonarezhou were predicted to relate to resource availability, primarily soil resources, as expected for semiarid savanna vegetation [32]. Similar results were obtained for other arid and semiarid regions [4]. The present study results confirmed strong dichotomy in savanna vegetation on whether plant growth is limited primarily by soil resource availability (dystrophic savannas) or by moisture (eutrophic savannas) and that is this pattern in a landscape scale as the case in Gonarezhou was related mainly to soil resource availability.

\section{Implications for Management}

Our study results contribute to the understanding of interactions of environmental determinants in shaping savanna ecosystems. Future studies should aim at establishing experimental plots in Gonarezhou to enable the monitoring of baobabs and assessment of results to determine how baobabs respond to different edaphic factors, disturbance regimes, and other growth factors. Knowledge of baobab abundance and spatial structural distribution in protected areas is useful in guiding restoration and management of natural habitats [7].

\section{Conflict of Interests}

The authors declare that they have no competing interest or financial interests.

\section{Acknowledgments}

The authors thank the Director General and Chief Ecologist of the Zimbabwe Parks and Wildlife Management Authority for supporting this study. They are also grateful to the Gonarezhou Conservation Project for all the logistic fieldwork support and the people who assisted in fieldwork, in particular, C. Mabika, D. Madhlamoto, T. Chinho, P. Nyabawa, and Gonarezhou staff, namely, C. Parakasingwa, O. Chipara, and S. Mavasa. C. Mashapa is greatly indebted to M. Liberty-Byron, M. Lisa-Briggs, and M. Leosa-Britney for their support.

\section{References}

[1] A. Guisan and N. E. Zimmermann, "Predictive habitat distribution models in ecology," Ecological Modelling, vol. 135, no. 2-3, pp. 147-186, 2000.

[2] K. J. Willis and R. J. Whittaker, "Ecology-species diversityscale matters," Science, vol. 295, no. 5558, pp. 1245-1248, 2002.

[3] M. Westoby, "Elements of a theory of vegetation dynamics in arid rangelands," Israel Journal of Botany, vol. 28, pp. 167-194, 1980.

[4] P. A. Aarrestad, G. S. Masunga, H. Hytteborn, M. L. Pitlagano, W. Marokane, and C. Skarpe, "Influence of soil, tree cover and large herbivores on field layer vegetation along a savanna landscape gradient in northern Botswana," Journal of Arid Environments, vol. 75, no. 3, pp. 290-297, 2011.

[5] K. M. Dunham, "Trends in populations of elephant and other large herbivores in Gonarezhou National Park, Zimbabwe, as revealed by sample aerial surveys," African Journal of Ecology, vol. 50, pp. 476-488, 2012.

[6] E. Gandiwa, G. Chikorowondo, P. Zisadza-Gandiwa, and J. Muvengwi, "Structure and composition of Androstachys johnsonii woodland across various strata in Gonarezhou National Park, Southeast Zimbabwe," Tropical Conservation Science, vol. 4, no. 2, pp. 218-229, 2011.

[7] M. T. Edkins, L. M. Kruger, K. Harris, and J. J. Midgley, "Baobabs and elephants in Kruger National Park: nowhere to hide," African Journal of Ecology, vol. 46, no. 2, pp. 119-125, 2007.

[8] K. Coates-Pelgrave, Trees of Southern Africa, Struik Publishers, Cape Town, South Africa, 1997.

[9] G. E. Wickens and P. Lowe, The Baobabs: Pachycauls of Africa, Madagascar and Australia, Springer, London, UK, 2008.

[10] C. T. Symes and M. R. Perrin, "Breeding biology of the Greyheaded Parrot (Poicephalus fuscicollis suahelicus) in the wild," Emu, vol. 104, no. 1, pp. 45-57, 2004.

[11] M. Westoby, B. Walker, and I. Noy-Meir, "Opportunistic management for rangelands not at equilibrium," Journal of Range Management, vol. 42, no. 4, pp. 266-274, 1989.

[12] Zimbabwe Parks and Wildlife Management Authority, General Management Plan Guideline For Gonarezhou National Park 2011-2021, Parks and Wildlife and Management Authority, Harare, Zimbabwe, 2011.

[13] E. Gandiwa and S. Kativu, "Influence of fire frequency on Colophospermum mopane and Combretum apiculatum woodland structure and composition in northern Gonarezhou National Park, Zimbabwe," Koedoe, vol. 51, no. 1, article \#685, 2009.

[14] B. H. Walker, "An approach to the monitoring of changes in the composition and utilisation of woodland and savanna vegetation," South African Journal of Wildlife Resources, vol. 6, no. 1, pp. 1-32, 1976.

[15] K. Nyamapfene, Soils of Zimbabwe, Nehanda Publishers, Harare Zimbabwe, 1991.

[16] B. Clegg, Vegetation Map of Northern Gonarezhou National Park, Malilangwe Trust, Chiredzi, Zimbabwe, 2003.

[17] W. D. Purves and M. J. Fullstone, Interim Report on the Soils of the Gonarezhou National Park: Lundi Subregion, Chemistry and soil research Institute, Ministry of Agriculture, Harare, Zimbabwe, 1975. 
[18] B. Y. Sherry, Basic Vegetation Types of the Gonarezhou National Park, Zimbabwe, Project No. GNP/3Y/2, Department National Parks and Wildlife Management, Harare, Zimbabwe, 1977.

[19] I. Mapaure, "The distribution of Colophospermum mopane in Africa," Kirkia, vol. 15, pp. 1-5, 1994.

[20] D. Mueller-Dombois and H. Ellenberg, Aims and Methods of Vegetation Ecology, John Wiley and Sons, New York, NY, USA, 1974.

[21] G. D. Anderson and B. H. Walker, "Vegetation composition and elephant damage in the Sebungwe Wildlife Research Area, Rhodesia," Journal of the South African Wildlife Management Association, vol. 4, no. 1, pp. 1-14, 1974.

[22] E. Mpofu, E. Gandiwa, P. Zisadza-Gandiwa, and H. Zinhiva, "Abundance, distribution and status of African baobab (Adansonia digitata L.) in dry savanna woodlands in southern Gonarezhou National Park, Southeast Zimbabwe," Tropical Ecology, vol. 53, no. 1, pp. 119-124, 2012.

[23] StatSoft, STATISTICA for Windows, Version 6. 2300, StatSoft, Tulsa, Okla, USA, 2001.

[24] K. McGarigal, S. Cushman, and S. Stafford, Multivariate Statistics for Wildlife and Ecology Research, Springer, New York, NY, USA, 2000.

[25] C. Mashapa, P. Nyabawa, P. Zisadza-Gandiwa, J. Muvengwi, S. Kativu, and E. Gandiwa, "Status of African baobab (Adansonia digitata) across Gonarezhou National Park, Zimbabwe," Journal of Applied Sciences and Environmental Management. In press.

[26] B. G. Wilson and E. T. F. Witkowski, "Seed banks, bark thickness and change in age and size structure (1978-1999) of the African savanna tree, Burkea africana," Plant Ecology, vol. 167, no. 1, pp. 151-162, 2003.

[27] A. M. Lykke, "Assessment of species composition change in savanna vegetation by means of woody plants' size class distributions and local information," Biodiversity and Conservation, vol. 7, no. 10, pp. 1261-1275, 1998.

[28] R. Condit, R. Sukumar, S. P. Hubbell, and R. B. Foster, "Predicting population trends from size distributions: a direct test in a tropical tree community," American Naturalist, vol. 152, no. 4, pp. 495-509, 1998.

[29] P. J. Grubb, “The maintenance of species-richness in plant communities: the importance of the regeneration niche," Biology Revision, vol. 52, pp. 107-145, 1977.

[30] Y. Guy, "The feeding behavior of elephants (Loxodonta africana) in Sebungwe area Rhodesia," South Africa Journal of Wildlife Management, vol. 6, pp. 55-63, 1976.

[31] C. Magadza, I. Coulson, and C. Tafangenyasha, "Ecology of Gonarezhou National Park," Progress Report GNP/B3/1a/1, Department of National Parks and Wildlife Management, Harare, Zimbabwe, 1993.

[32] R. J. Scholes and B. H. Walker, An African Savanna: Synthesis of the Nylsvley Study, Cambridge University Press, Cambridge, UK, 1993. 

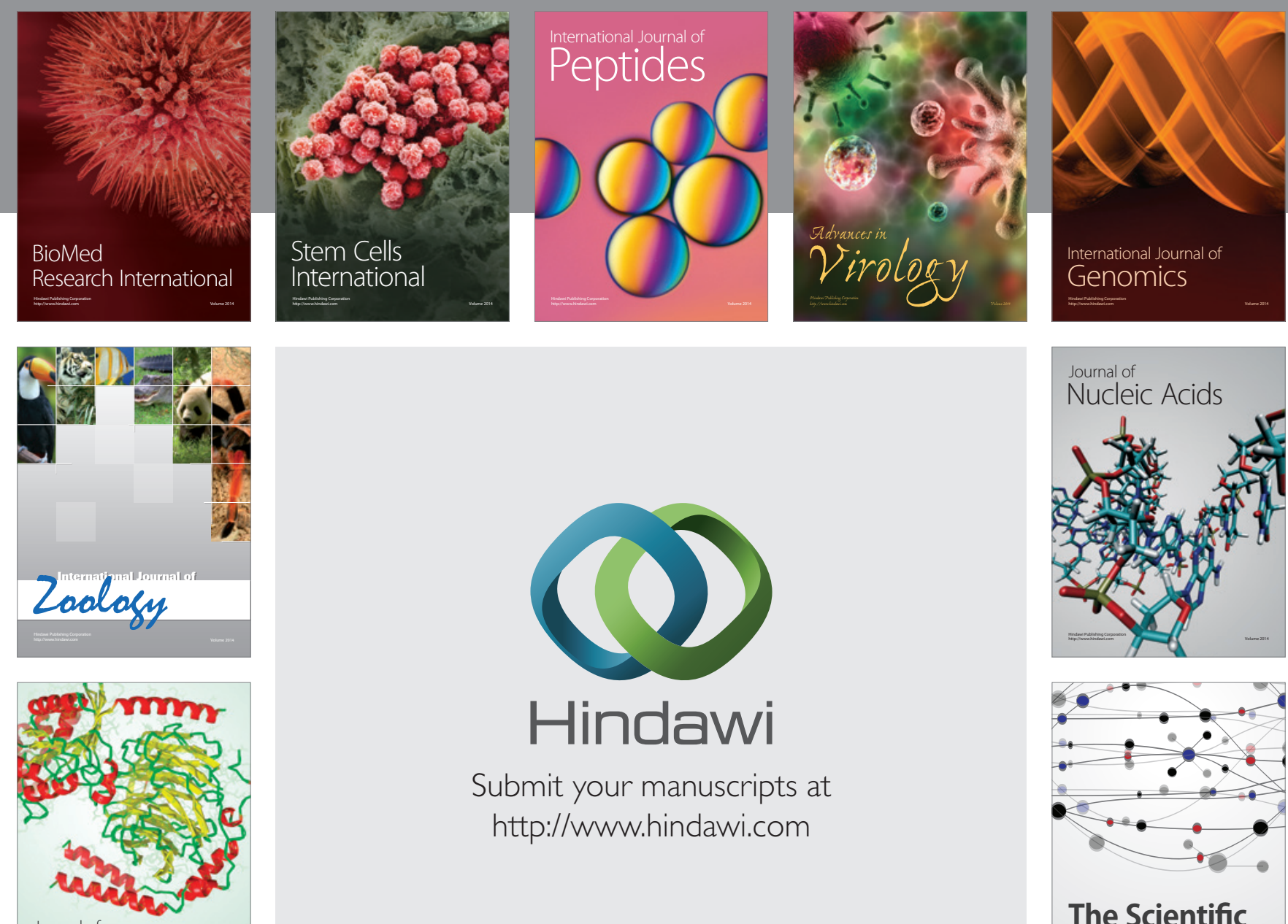

Submit your manuscripts at

http://www.hindawi.com

Journal of
Signal Transduction
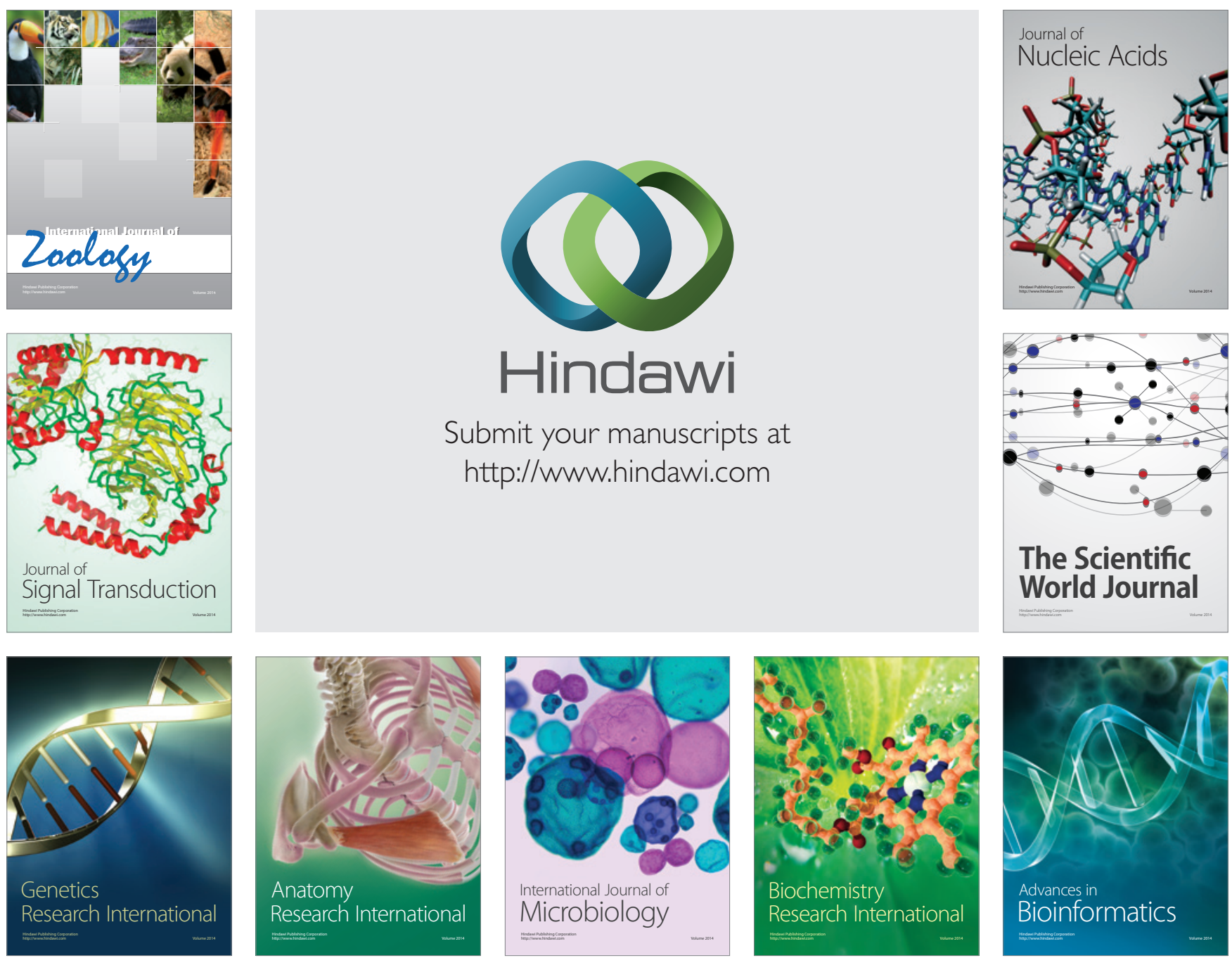

The Scientific World Journal
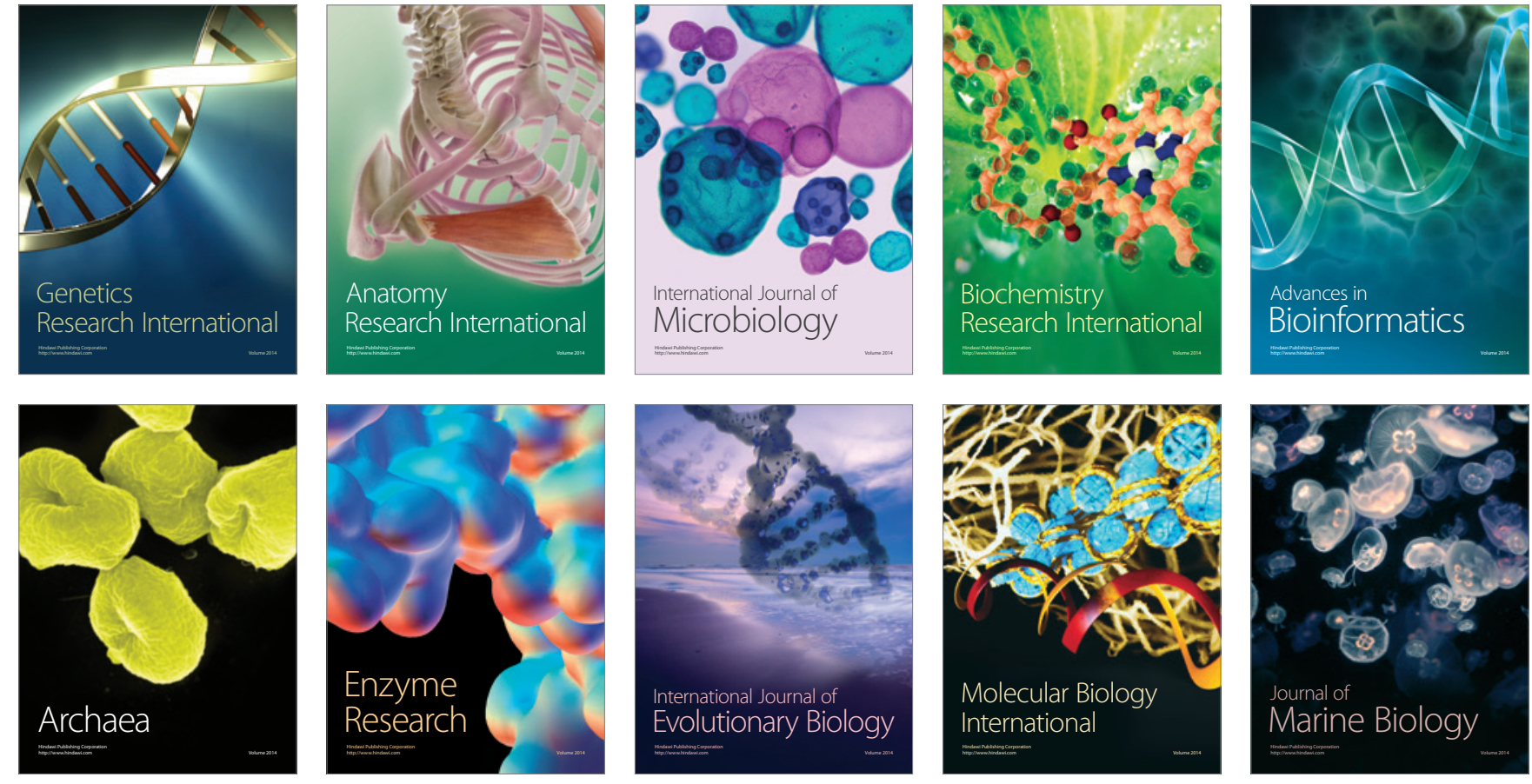